\title{
The exometabolome of Clostridium thermocellum reveals overflow metabolism at high cellulose loading
}

Evert K Holwerda ${ }^{1,2}$, Philip G Thorne ${ }^{3}$, Daniel G Olson ${ }^{1,2}$, Daniel Amador-Noguez ${ }^{4}$, Nancy L Engle ${ }^{2,5}$, Timothy J Tschaplinski ${ }^{2,5}$, Johannes P van Dijken ${ }^{6}$ and Lee R Lynd ${ }^{1,2,3^{*}}$

\begin{abstract}
Background: Clostridium thermocellum is a model thermophilic organism for the production of biofuels from lignocellulosic substrates. The majority of publications studying the physiology of this organism use substrate concentrations of $\leq 10 \mathrm{~g} / \mathrm{L}$. However, industrially relevant concentrations of substrate start at $100 \mathrm{~g} / \mathrm{L}$ carbohydrate, which corresponds to approximately $150 \mathrm{~g} / \mathrm{L}$ solids. To gain insight into the physiology of fermentation of high substrate concentrations, we studied the growth on, and utilization of high concentrations of crystalline cellulose varying from 50 to $100 \mathrm{~g} / \mathrm{L}$ by C. thermocellum.

Results: Using a defined medium, batch cultures of C. thermocellum achieved 93\% conversion of cellulose (Avicel) initially present at $100 \mathrm{~g} / \mathrm{L}$. The maximum rate of substrate utilization increased with increasing substrate loading. During fermentation of $100 \mathrm{~g} / \mathrm{L}$ cellulose, growth ceased when about half of the substrate had been solubilized. However, fermentation continued in an uncoupled mode until substrate utilization was almost complete. In addition to commonly reported fermentation products, amino acids - predominantly L-valine and L-alanine - were secreted at concentrations up to $7.5 \mathrm{~g} / \mathrm{L}$. Uncoupled metabolism was also accompanied by products not documented previously for C. thermocellum, including isobutanol, meso- and RR/SS-2,3-butanediol and trace amounts of 3-methyl-1-butanol, 2-methyl-1-butanol and 1-propanol. We hypothesize that C. thermocellum uses overflow metabolism to balance its metabolism around the pyruvate node in glycolysis.

Conclusions: $C$. thermocellum is able to utilize industrially relevant concentrations of cellulose, up to $93 \mathrm{~g} / \mathrm{L}$. We report here one of the highest degrees of crystalline cellulose utilization observed thus far for a pure culture of C. thermocellum, the highest maximum substrate utilization rate and the highest amount of isobutanol produced by a wild-type organism.
\end{abstract}

Keywords: Clostridium thermocellum, Cellulose fermentation, Isobutanol, 2,3-butanediol, Amino acids, High solids, Fusel alcohols

\section{Background}

Clostridium thermocellum is a model organism for the production of cellulosic biofuels in a consolidated bioprocessing (CBP) configuration, because of its plant cell wall-solubilizing enzyme complex, the cellulosome, and its ability to ferment cellodextrins to ethanol [1-3]. Although this organism has been studied for more than

\footnotetext{
* Correspondence: lee.r.lynd@dartmouth.edu

${ }^{1}$ Thayer School of Engineering, Dartmouth College, Hanover, NH 03755, USA

${ }^{2}$ BioEnergy Science Center, Oak Ridge, TN 37830, USA

Full list of author information is available at the end of the article
}

60 years [4], there are still many gaps in our understanding of its physiology. For example, formate production was reported by McBee in 1954 [5], but it took more than 50 years before formate was shown to be a significant fermentation end product [6]. Ellis et al. reported in 2012 that $C$. thermocellum produces extracellular amino acids in significant amounts [7]. The concentrations of extracellular amino acids increased when metabolic pathways for lactate and acetate were knocked out [8]. With a combination of gene deletions and enzymatic assays it has been shown that $C$. thermocellum has atypical glycolysis 
and lacks pyruvate kinase [9]. The recent development and application of genetic tools [10-12] has accelerated both applied and fundamental investigations of this organism.

Most of our current understanding of C. thermocellum physiology is based on fermentations with carbohydrate loadings of $<10 \mathrm{~g} / \mathrm{L}$ [7,13-31]. There are, however, a few notable exceptions. Tailliez et al. cultured a mutated strain of C. thermocellum that utilized $63 \mathrm{~g} / \mathrm{L}$ out of $70 \mathrm{~g} / \mathrm{L}$ cellulose (MN300) and produced $14.5 \mathrm{~g} / \mathrm{L}$ ethanol [32]. Wang et al. used a fed-batch cellulose fermentation with a maximum utilization of $35 \mathrm{~g} / \mathrm{L}$ cellulose (Solka-Floc ${ }^{\circ}$ ) to test mutant strains of $C$. thermocellum. Their study also included a co-culture of $C$. thermocellum with Thermoanaerobacterium thermosaccharolyticum that grew on 80 $\mathrm{g} / \mathrm{L}$ solids (Solka-Floc) with three quarters of the substrate utilized and a $100 \mathrm{~g} / \mathrm{L}$ cornstover co-culture with $37 \%$ of the substrate utilized [33]. Hogsett reported a set of sequential high solids fermentations with initial cellulose loadings of 26,47 , and $72 \mathrm{~g} / \mathrm{L}$ and a maximum cellulose utilization of $65 \mathrm{~g} / \mathrm{L}$ [34].

Clostridium thermocellum strains are routinely isolated from saccharolytic microbial communities [4,35,36], and some lab strains of $C$. thermocellum have turned out to be stable co-cultures of cellulolytic and non-cellulolytic species [37-39]. It has been hypothesized that this stability may be due to cross-feeding of vitamins and other compounds between strains $[40,41]$, with positive effects on the fermentation of cellulose $[42,43]$. The beneficial effects of co-culturing were recently also demonstrated by Argyros et al., who showed that a co-culture of engineered strains of $C$. thermocellum and T. saccharolyticum was able to ferment $83 \mathrm{~g} / \mathrm{L}$ of cellulose into an impressive 38 $\mathrm{g} / \mathrm{L}$ ethanol $(80 \%$ of the theoretical maximum), while a pure culture of the same $C$. thermocellum strain produced only $14 \mathrm{~g} / \mathrm{L}$ of ethanol when cultured on $40 \mathrm{~g} / \mathrm{L}$ cellulose [10]. Application in industrial processes is likely to require carbohydrate concentrations of $100 \mathrm{~g} / \mathrm{L}$ carbohydrate or more [44], corresponding to lignocellulose loadings of at least $150 \mathrm{~g} / \mathrm{L}$ on a dry matter basis.

This work was undertaken to study the physiology of $C$. thermocellum at high cellulose loading to guide further metabolic engineering aimed at improvement of ethanol production.

\section{Results and discussion}

\section{Fermentation of increasing cellulose loadings}

Three different substrate loadings (50, 70 and $100 \mathrm{~g} / \mathrm{L})$ of crystalline cellulose (Avicel PH105) were tested under the same fermentation conditions and nutrient concentrations (Figure 1). Out of the three substrate loadings only the $100 \mathrm{~g} / \mathrm{L}$ loading did not reach full conversion of the substrate (not shown in Figure 1). Repeated $100 \mathrm{~g} / \mathrm{L}$ fermentations $(n=3)$ showed that the conversion was stable around $80 \%$ of $100 \mathrm{~g} / \mathrm{L}$ (see Table 1 ). Addition of nitrogen to the growth medium in the form of ammonium sulfate $\left(5 \mathrm{~mL}^{*} 200 \mathrm{~g} / \mathrm{L}\left(\mathrm{NH}_{4}\right)_{2} \mathrm{SO}_{4}\right)$, ammonium hydroxide (14.8 $\mathrm{N} \mathrm{NH}_{4} \mathrm{OH}$ ) as base addition for $\mathrm{pH}$ control, and urea $\left(8 \mathrm{~mL}^{*} 500 \mathrm{~g} / \mathrm{L}\left(\mathrm{NH}_{2}\right)_{2} \mathrm{CO}\right)$ did not increase conversion. Cysteine, added as a reducing agent to the medium, can be a possible secondary source of nitrogen and sulfur to cells. Measuring nitrogen in the form of urea or ammonia $\left(\mathrm{NH}_{3}\right)$ via enzymatic assay showed the presence of residual nitrogen in the medium, which confirmed that the lack of complete conversion of the substrate was not caused by nitrogen limitation.

For various time points, the supernatant of the fermentation broth was analyzed for trace metals/elements $\mathrm{B}, \mathrm{Mn}^{2+}, \mathrm{Co}^{2+}, \mathrm{Ni}^{2+}, \mathrm{Cu}^{2+}, \mathrm{Zn}^{2+}, \mathrm{Mo}^{2+}, \mathrm{Na}^{+}, \mathrm{Fe}^{2+}, \mathrm{Mg}^{2+}$, and $\mathrm{Ca}^{2+}$ and the vitamins pyridoxamine- $2 * \mathrm{HCL}$, cyanocobalamin $\left(\mathrm{B}_{12}\right)$ and para-aminobenzoic acid (PABA). Biotin was not assayed (see Methods). Trace elements were detected throughout the duration of the fermentation, although $\mathrm{Cu}^{2+}$ and $\mathrm{Mn}^{2+}$ decreased in concentration during the fermentation. Doubling the trace elements solution did not result in an increase in substrate utilization. Vitamin $\mathrm{B}_{12}$ was not detected in the fermentation broth by the vitamin B panel analysis, but was detected at the correct concentration in the stock solution. The pyridoxamine$2 * \mathrm{HCl}$ concentration decreased to zero at $50 \%$ conversion, and niacinamide (vitamin $\mathrm{B}_{3}$ ) was detected halfway through the fermentation. It was not clear how the analysis failed to detect vitamin $B_{12}$ in the medium during the fermentation process. To avoid pyridoxamine depletion and to control for the effect of possible spontaneous degradation of vitamin $\mathrm{B}_{12}$ under fermentation conditions, fresh vitamin solution was added at several times during the fermentation, rather than all at once in the beginning. By adding supplemental vitamins at four different times (Figure 1) during the fermentation, substrate utilization increased to $93 \%$. Vitamin analysis showed pyridoxamine present at all time points, but neither vitamin $B_{12}$ nor $B_{3}$ was detectable.

C. thermocellum achieved complete conversion at substrate loadings up to $70 \mathrm{~g} / \mathrm{L}$ and initially achieved $80 \%$ conversion at substrate loadings of $100 \mathrm{~g} / \mathrm{L}$. The addition of extra aliquots of vitamins alleviated restrictions, and utilization increased from $80 \%$ to $93 \%$ for $100 \mathrm{~g} / \mathrm{L}$ substrate loadings. Whether this was due solely to depleted pyridoxamine, or whether other vitamins also played a role would require a more detailed analysis. The standard concentration of vitamins used for the experiments discussed here is according to Hogsett [34] and is ten times higher than that described by Johnson et al. [15]. The highest amount of utilized cellulose we observed was $96.7 \mathrm{~g} / \mathrm{L}$ out of $103.4 \mathrm{~g} / \mathrm{L}$ (about 94\%, see Table 1), one of the highest values reported for a pure culture of C. thermocellum thus far [45]. 


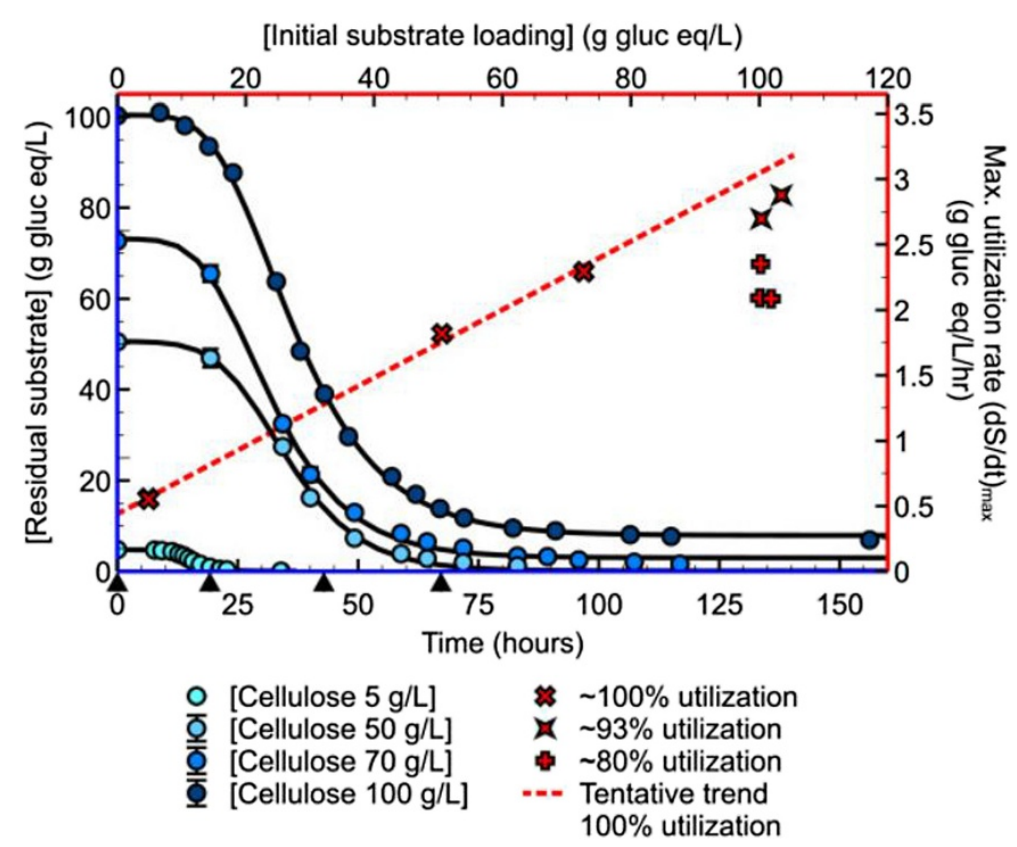

Figure 1 Residual substrate concentrations for 5, 50, 70, and $100 \mathrm{~g} / \mathrm{L}$ cellulose in gram glucose equivalents/L, and maximum substrate utilization rates versus initial substrate loading. Black triangles on the bottom $x$-axis indicate time points where additional vitamins were added for the $100 \mathrm{~g} / \mathrm{L}$ fermentation. An additional data set of a $5 \mathrm{~g} / \mathrm{L}$ cellulose fermentation is added. For accurate substrate values shown here, see Table 1.

Rates of cellulose utilization

The fermentation data for all three high cellulose loadings and the $5 \mathrm{~g} / \mathrm{L}$ fermentation in Figure 1 have been fitted with a sigmoidal curve [29], from which a maximum rate was determined and plotted versus the initial substrate loading (Figure 1). The increase of the utilization rate with the increase in substrate loading of 5 to $70 \mathrm{~g} / \mathrm{L}$ fermentations (these fermentations reached about 100\% conversion, see Table 1) is fitted with a straight line. Data points for five $100 \mathrm{~g} / \mathrm{L}$ initial cellulose loadings are also

Table 1 Initial and final substrate concentrations and rate data for all fermentations shown in Figure 1

\begin{tabular}{cccc}
\hline $\begin{array}{l}\text { Initial } \\
\text { [substrate] } \\
\text { (g gluc eq/L) }\end{array}$ & $\begin{array}{l}\text { Final } \\
\text { [substrate] } \\
\text { (g gluc eq/L) }\end{array}$ & $\begin{array}{l}\text { Utilized } \\
\text { (g gluc eq/L) } \\
\text { (\% utilization) }\end{array}$ & $\begin{array}{l}\text { Maximum substrate } \\
\text { utilization rate } \\
\text { (g gluc eq/L/hr) }\end{array}$ \\
\hline 4.8 & 0.04 & $4.76(99)$ & 0.56 \\
50.6 & 0 & $50.6(100)$ & 1.82 \\
72.7 & 0.72 & $71.08(99)$ & 2.29 \\
100.2 & 19.2 & $81(81)$ & 2.35 \\
100.1 & 22.6 & $77.5(77)$ & 2.09 \\
101.8 & 19.1 & $82.7(81)$ & 2.09 \\
100.3 & 6.9 & $93.4(93)$ & 2.70 \\
103.4 & 6.7 & $96.7(94)$ & 2.88
\end{tabular}

Actual concentrations of substrate are shown in gram glucose equivalents/L (g gluc eq/L) since Avicel PH105 contains xylose and insoluble residual content, and has a moisture content of around $5 \%$. The three categories of maximum substrate utilization rates shown in Figure 1 are based on percentage utilization as shown here (approximately $80 \%$ utilization, 93\% utilization and $100 \%$ utilization). shown; three fermentations reached $80 \%$ conversion and two reached 93\% conversion (see Table 1). The maximum utilization rates for the $80 \%$ conversion fermentations are lower than those for the $93 \%$ conversion fermentations, although all fermentations started with the same substrate loadings (corresponding to equal available substrate surface area). An increase in utilization because of increased vitamins also resulted in an increased maximum utilization rate, and the utilization rates of the two approximately 93\% fermentations are close to the fitted curve, based on the data for lower initial substrate concentration at which 100\% conversion was observed.

The time it takes to utilize $50 \mathrm{~g} / \mathrm{L}$ or $93 \mathrm{~g} / \mathrm{L}$ is very similar with the same size inoculum $(0.5 \%)$, as is shown by the increasing maximum rate of substrate utilization with increasing solids loading (except for the $100 \mathrm{~g} / \mathrm{L}$ : $80 \%$ conversion, non-optimized fermentations, where the rate is equal to or lower than that of the $70 \mathrm{~g} / \mathrm{L}$ substrate loading). The maximum substrate utilization rate at $100 \mathrm{~g} /$ $\mathrm{L}$ loading (about $2.9 \mathrm{~g} / \mathrm{L} / \mathrm{h}$ ) is among the highest reported for a pure culture of C. thermocellum (2.5 g/L/h, [34]).

\section{Carbon balance for commonly reported end products}

Carbon balances based on the commonly reported fermentation products acetate, ethanol, formate, lactate, cells and carbon dioxide were made for all four different substrate loadings and are shown in Figure 2 (more detailed time courses for the fermentation end products acetate, ethanol, lactate and formate of C. thermocellum 


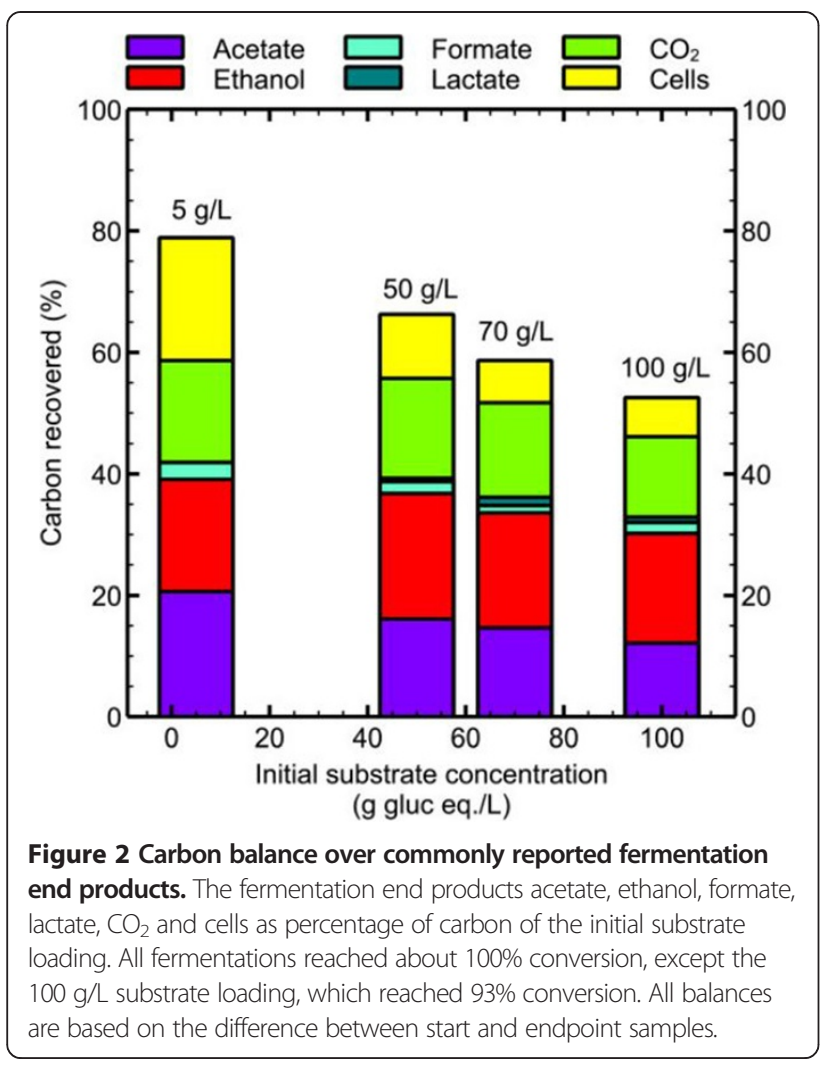

for the optimized $100 \mathrm{~g} / \mathrm{L}$ fermentation are shown in Figure 3B). With increasing substrate loading the relative amount of carbon accounted for in these end products decreased from $79 \%$ to $53 \%$.

\section{Cells, residual substrate nitrogen, amino acids and protein}

Both pellet protein and pellet nitrogen, considered to be proxies for cell concentration, were measured for the optimized $100 \mathrm{~g} / \mathrm{L}$ cellulose fermentation with multiple additions of vitamins. At around 50\% substrate conversion, the cells stop growing as indicated by the arrows in Figure 3. The remainder of the substrate was nevertheless utilized. At 50\% conversion, approximately one-third of the initial medium nitrogen was still present (Figure 3C), and after cell growth stopped the culture utilized a significant amount of additional medium nitrogen. The amount of nitrogen present in cell biomass did not account for all the nitrogen utilized. During and after the cell growth phase, there is a non-trivial amount of nitrogen incorporated into free amino acids; $7.5 \mathrm{~g} / \mathrm{L}$ of amino acids in total for the fermentation of $93 \mathrm{~g} / \mathrm{L}$ cellulose utilized, with L-valine and L-alanine predominant at $4.5 \mathrm{~g} / \mathrm{L}$ and $1.5 \mathrm{~g} / \mathrm{L}$ respectively (see Figure $3 \mathrm{C}$ ). The amount of supernatant and pellet protein nitrogen is plotted together with the amount of amino acid nitrogen in Figure 3D. It was determined that about $60 \%$ of nitrogen that is being taken up by cells is incorporated into extracellular amino acids.
The presence of amino acids in C. thermocellum fermentation broth has been reported before, although at lower concentrations and at lower substrate loadings $[7,8,46]$. Pyruvate serves as a precursor for both L-valine $(4.5 \mathrm{~g} / \mathrm{L})$ and L-alanine (1.5 g/L) [8] (see Figure 4), the two amino acids produced in the highest concentrations. Other amino acids were produced in significantly lower concentrations; L-glutamate $(0.62 \mathrm{~g} / \mathrm{L})$, L-isoleucine $(0.24 \mathrm{~g} / \mathrm{L})$, L-leucine $(0.17 \mathrm{~g} / \mathrm{L})$, all other measured amino acids did not exceed $100 \mathrm{mg} / \mathrm{L}$. Secreting amino acids is common for rumen bacteria, with L-alanine and L-valine among the most prevalent [47]. L-alanine is a major end product for Pyrococcus furiosus during growth on various carbohydrates [48]. A number of other Clostridia species excrete amino acids during the growth phase [49], and Gram-positive bacteria have ten to twenty times higher intracellular amino acids pools than Gram-negative bacteria [50]. It is noteworthy that $C$. thermocellum also contains high amounts of branched-chain fatty acids, which indicates a link for branched-chain fatty acids and branched-chain amino acids L-valine, L-leucine and L-isoleucine [51].

Cessation of growth and decrease in cell concentration for C. thermocellum have been observed previously at much lower substrate concentrations and much closer to full substrate conversion than seen here $[33,46]$. This decrease was attributed to starvation due to decreased access to substrate (reduced accessible surface area) [29]. The decrease in biomass concentration observed here after cessation of cell growth was more rapid for pellet nitrogen than for pellet protein (see Methods and Figure 3A), for which there is no clear explanation.

While the cessation of cell growth due to limitation by nitrogen, vitamins or trace elements is unlikely, limitation of other essential nutrients cannot be ruled out. Accumulation of inhibitory end products and the creation of an ion imbalance can cause cell growth and fermentation to stop [52,53]. However, in our experiments, fermentation was not affected, while biomass ceased to increase. Cellcell interactions like the quorum sensing mechanism can also impact cell growth. Steiner et al. recently found a set of quorum sensing genes in C. acetobutylicum [54]. Burell described a species-specific quorum sensing mechanism for a $C$. thermocellum-like isolate from landfill biomass leachate [55], and Wilson et al. reported on a gene in C. thermocellum with putative peptide quorum sensing function [56].

\section{Additional fermentation products}

During the analysis of fermentation products it became evident that there were more compounds present than there are traditionally attributed to the metabolism of C. thermocellum. Identification of these compounds was undertaken, initially based on matching peak residence times to known compounds using gas and liquid 


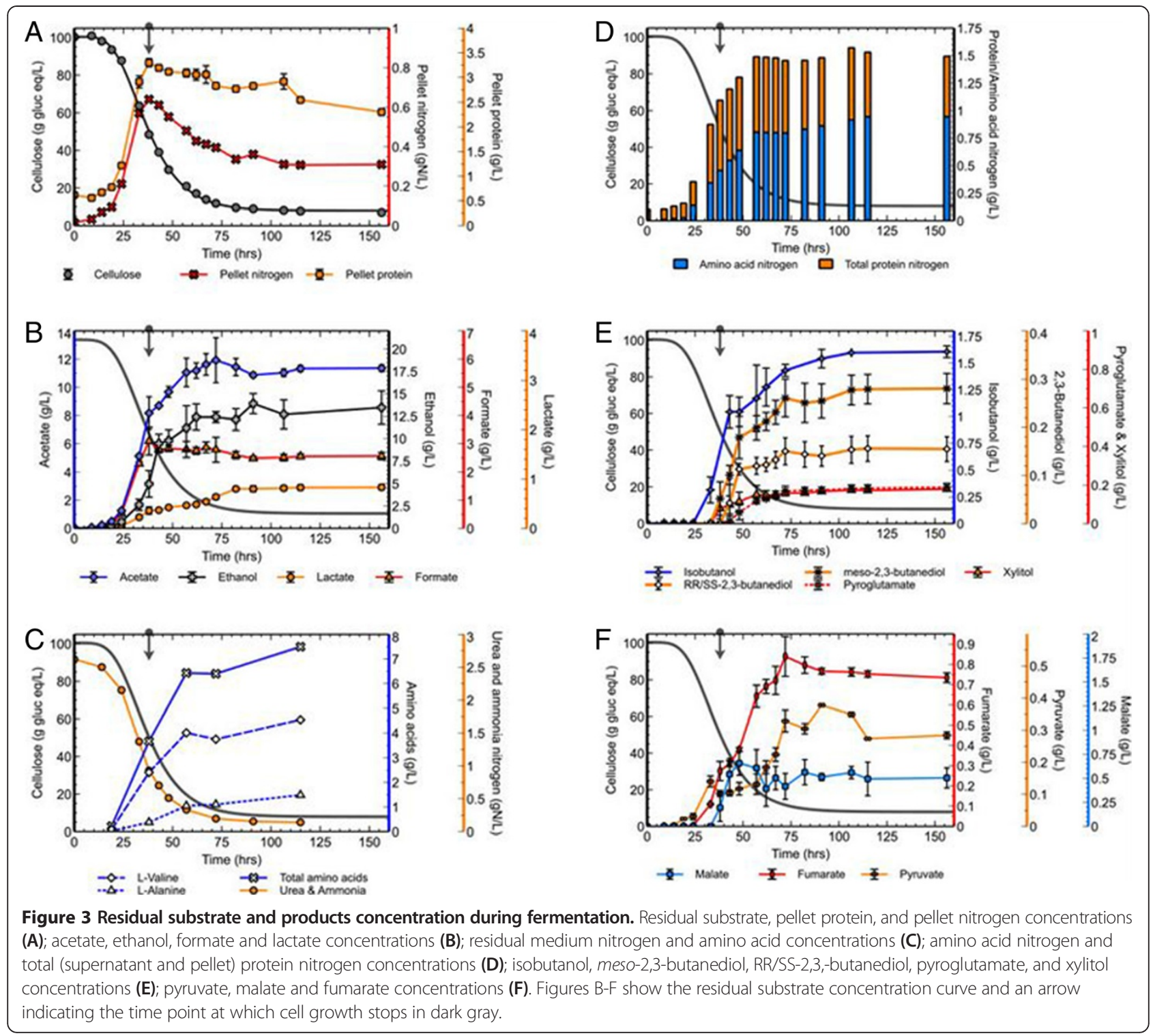

chromatography with conformation based on mass spectroscopy (see Additional files 1: Figure S1A, 2: Figure S1B, 3: Figure S2A, 4: Figure S2B, 5: Figure S2C, 6: Figure $\mathrm{S} 2 \mathrm{D})$. Isobutanol and 2,3-butanediols appeared before cell growth stopped (Figure 3E); however, their occurrence did not coincide. Other compounds detected in significant amounts included pyroglutamate, xylitol (Figure 3E), pyruvate, fumarate and malate (Figure 3F). Trace amounts of 1,2,3-butanetriol, 2-methyl-1-butanol (2M1B), 3-methyl-1-butanol (3M1B), and 1-propanol were also detected in fermentation end-samples. Further analysis revealed that both the chiral forms of 2,3-butanediol (SS-I RR-) as well as meso-2,3-butanediol were present. Small quantities of xylose (present in low amounts in Avicel PH105) and glucose (as a monomer and in cellodextrins) accumulated towards the end of the fermentation.
Xylitol as a product of (ligno)cellulosic fermentation has been reported for yeast [57,58]. However, it is unclear whether the xylitol found here has strict bacterial origins, or is the result of the abiotic breakdown process of the substrate and interactions with fermentation broth constituents. Pyroglutamate, also known as pyrrolidone carboxylic acid, can be the product of spontaneous degradation reactions of glutamine and of glutamic acid that accelerate at higher temperatures $[59,60]$. It should be noted that pyroglutamate could have inhibitory effects on growth at high temperatures [61].

Isobutanol biosynthesis branches off from the L-valine biosynthesis pathway in similar ways, 1-propanol and 2methyl-1-butanol branch off from the threonine/isoleucine biosynthesis pathway, and 3-methyl-1-butanol from the leucine pathway (see Figure 4 and [www.genome.jp/ 


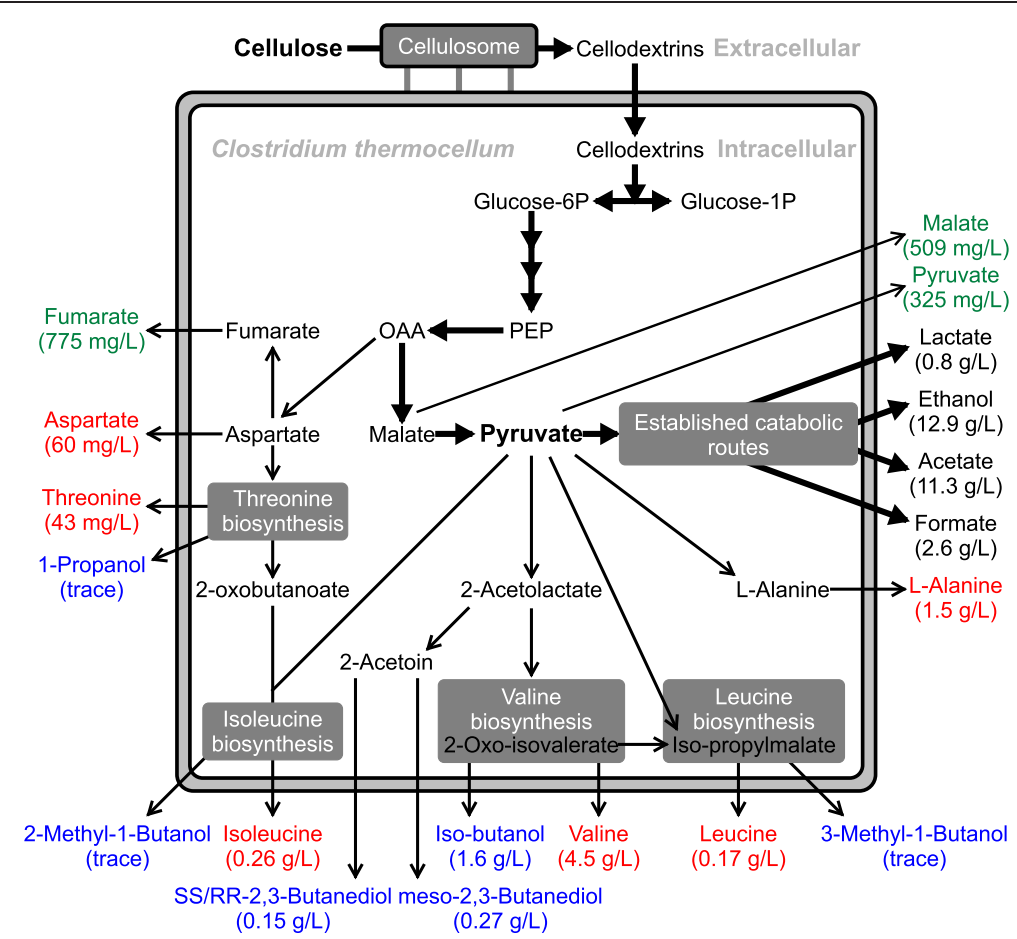

Figure 4 Fermentation end products and concentrations in an abridged pathway diagram. Commonly reported compounds (black), amino acids (red), metabolic intermediates (green) and higher alcohols (blue). Bold arrows represent the main catabolic route.

kegg/]) [62,63]. The alcohols formed in this manner are called fusel alcohols, and the pathway in yeast is known as the Ehrlich pathway. Production of fusel alcohols has not been observed previously for C. thermocellum, and no specific genes for isobutanol or fusel-alcohol pathways are annotated in the C. thermocellum genome [64].

While 1-propanol, 1,2,3,-butanetriol, 2M1B and 3M1B were detected in trace amounts, isobutanol and the butanediols were found in noticeable quantities. There are two ways for isobutanol to be formed from 2-oxo-isovalerate/ 2-keto-isovalerate from the L-valine biosynthesis pathway (Figure 4): either by a keto-acid decarboxylation reaction into isobutyraldehyde followed by a reduction to isobutanol, or via a keto-acid dehydrogenase reaction into isobutyryl-CoA via a dehydrogenase reaction into isobutylaldehyde and finally by an alcohol dehydrogenase into isobutanol. The only other cellulolytic anaerobe reported to be capable of producing isobutanol is an engineered strain of $C$. cellulolyticum with a maximum concentration of $660 \mathrm{mg} / \mathrm{L}$ isobutanol based on a solids loading of $10 \mathrm{~g} / \mathrm{L}$ cellulose [63].

The appearance of 2,3-butanediol, although in small quantities, is interesting as this would be the first and only example of a thermophilic, cellulolytic microorganism producing 2,3-butanediol [65]. Both the chiral form (RR-/SS-) as well as the meso- form of 2,3-butanediol were found, and it is common for wild-type organisms to produce both the meso and one of the two chiral molecules [66]. The pathway for the biosynthesis of 2,3butanediols branches off from the central metabolism via 2 -acetolactate at the pyruvate node (see Figure 4 ). $C$. thermocellum has no annotation of any activity involved in the 2,3-butandiol pathway (as part of the butanoate pathway) from 2-acetolactate onwards. Pathways that include meso-2,3-butanediol have been discussed by Siemerink et al. [67]. C. thermocellum has been used in producing 2,3-butanediol from lignocellulosic substrate but this was in a co-culture in which Klebsiella pneumoniae was responsible for generating butanediol [68].

The appearance of these metabolites questioned the purity of the culture. However, 16S rRNA testing, as described in the Methods section, did not result in any irregularities. The 93\% conversion-vitamin complemented fermentation discussed here proved to be pure from inoculum throughout the fermentation until the final sample. Further studies are required to establish the nature of the enzymes by which these non-common products are formed and to what extent this is affected by medium components such as citrate and cysteine.

\section{Overflow metabolism around the pyruvate node}

It is not uncommon to find pyruvate in C. thermocellum fermentations, even at lower concentrations of substrate $[7,10,11]$. The concentration of pyruvate found here is relatively low $(325 \mathrm{mg} / \mathrm{L}$, see Figure $3 \mathrm{~F}$ and Figure 4). The additional presence of the glycolysis/citric acid cycle 
intermediates malate $(509 \mathrm{mg} / \mathrm{L})$ and fumarate $(775 \mathrm{mg} / \mathrm{L})$ indicates metabolic imbalance (Figure 3F) $[9,69]$. Desvaux et al. reported that C. cellulolyticum stopped growing in a defined medium before complete utilization of substrate when cultured on concentrations higher than $6.7 \mathrm{~g} / \mathrm{L}$ cellulose. Pyruvate accumulation was reported as well [70]. According to their hypothesis, this was caused by the rate of cellulose catabolism exceeding that of pyruvate consumption, leading to an accumulation of intracellular inhibitory compounds. Guedon et al. were able to resolve the metabolism and pyruvate overflow of C. cellulolyticum by introducing the Zymomonas mobilis genes for pyruvate decarboxylase and alcohol dehydrogenase II, resulting an increase in biomass growth and a changed fermentation pattern [71].

All the previously known and newly identified fermentation end products depart from central metabolism at, or downstream of, the pyruvate node, as shown in Figure 4. Around the time that cell growth stops, the carbon flux towards commonly reported fermentation end products decreased (Figure 3B) and flux towards other products increased (Figures $3 \mathrm{~B}$ and $3 \mathrm{~F}$ ). The appearance of malate, fumarate, pyruvate and isobutanol happens prior to the cessation in cell growth (Figure 3A,E,F). The 2,3-butanediols, pyroglutamate and xylitol appear around the time cell growth stops. An apparent bottleneck exists around the pyruvate node in $C$. thermocellum metabolism, and amino acid and $\mathrm{C}_{4}$-solvent production could be a strategy to channel away catabolic intermediates in an attempt to maintain a balanced metabolism. Conclusive proof of this hypothesis will require further experimentation.

We speculate that the very high production of amino acids by $C$. thermocellum reported here is unlikely to occur in nature, but rather is a result of the organism being cultivated under conditions different from those encountered in nature. Among such differences, the absence of other microbial species and the very high substrate and nutrient concentrations seem particularly notable to us. Consumption of carbohydrate fermentation products, in particular $\mathrm{H}_{2}$ consumption by methanogens, is known to have large effects on the metabolism of $C$. thermocellum and other saccharolytic microbes $[10,13,42,72,73]$. In the absence of such consumption and in the presence of very high carbon source concentrations, products accumulate to levels not seen in natural environments, and this accumulation may well trigger metabolic responses. Interspecies cross-feeding is an important source of vitamins in natural environments [40,41,43]. The requirement of $C$. thermocellum for vitamins in pure culture, previously reported $[15,34]$ and also observed here, is likely an indication of this organism existing in nature in close association with other microbes.
Future work co-culturing $C$. thermocellum with other organisms, either a saccharolytic species or a methanogen, would be of interest. Amino acids were not reported by Argyros et al. [10], or in any other co-culture study to our knowledge. It appears that the electron and carbon recovery for co-cultures with saccharolytic thermophiles and $C$. thermocellum is higher than that for pure C. thermocellum cultures [33].

After accounting for all measured components, the carbon balances for 50, 70 and $100 \mathrm{~g} / \mathrm{L}$ cellulose loadings increased from $66.3 \%, 58.7 \%$ and $52.5 \%$ (Figure 2) to $96.1 \%, 78.1 \%$ and $80.8 \%$, respectively, showing that for the higher concentrations of cellulose still other metabolites remain to be discovered.

\section{Conclusions}

Clostridium thermocellum is able to utilize up to $96.7 \mathrm{~g} / \mathrm{L}$ out of $103.4 \mathrm{~g} / \mathrm{L}$ cellulose substrate initially present in a defined medium and under controlled conditions. The maximum rate of substrate utilization increases with increasing substrate loading up to $2.9 \mathrm{~g}$ glucose $/ \mathrm{L} / \mathrm{h}$, and is one of the highest rates reported. A concentration of $100 \mathrm{~g} / \mathrm{L}$ cellulose is equivalent to about $150 \mathrm{~g} / \mathrm{L}$ of lignocellulosic material based on carbohydrate content, and this result shows that unmodified $C$. thermocellum is able to ferment industrially relevant carbohydrate loadings on a defined medium.

The presence of higher alcohols as fermentation end products is indicative of previously unrecognized metabolic diversity. Further investigation is needed to determine which genes are involved in formation of these overflow metabolites. It would be relevant in this respect to grow $C$. thermocellum with a suitable co-culture partner strain on high cellulose loadings to see whether overflow metabolism occurs and whether cross-feeding of vitamins can eliminate the need for supplemental addition of vitamins during the course of the fermentation.

To our knowledge, this is the first time that SS/RR-/ meso-2,3-butanediol and isobutanol have been reported as products of the metabolism of Clostridium thermocellum or any cellulolytic, thermophilic wild-type microbe cultured on cellulose. The isobutanol concentration of $1.6 \mathrm{~g} / \mathrm{L}$ is the highest isobutanol concentration observed for a wild-type organism.

\section{Methods}

\section{Organism and culture purity}

Clostridium thermocellum DSM 1313 was grown on $5 \mathrm{~g} / \mathrm{L}$ cellulose in Medium for Thermophilic Clostridia (MTC) $[34,46]$ and stored in $5-\mathrm{mL}$ aliquots at $-80^{\circ} \mathrm{C}$. The purity of the culture was tested using commercially available 16S rRNA primers from Integrated DNA Technologies (IDT, Coralville IA) (forward primer: AGA GTT TGA TCC TGG CTC AG, reverse primer: ACG GCT ACC 
TTG TTA CGA CTT). PCR products were sequenced (GENEWIZ Inc.) and compared to the genomes of $C$. thermocellum DSM 1313 and ATCC 27405. No contamination was detected before, during, or at the end of the fermentations described here.

\section{Bioreactor cultivation}

MTC without MOPS buffer was prepared as described previously [46] and contained $5 \mathrm{~g} / \mathrm{L}$ urea as the nitrogen source. Fermentations were carried out in 2.5- and 1.5-L (1-L working volume) Sartorius Biostat A-plus Sartorius Stedim (Sartorius Stedim, Bohemia, NY) bioreactors with the temperature maintained at $60^{\circ} \mathrm{C}$ and stirred at 300 rpm. The $\mathrm{pH}$ was controlled at 7.0 with a Mettler-Toledo $\mathrm{pH}$ probe (Columbus, $\mathrm{OH}$ ) by the addition of $14.8 \mathrm{~N}$ $\mathrm{KOH}$. Base addition, $\mathrm{pH}$ and temperature were recorded by the bioreactor setup described in [46]. For vitamin supplementation, aliquots of a 50-fold concentrated vitamin-solution were added at designated time points.

Cellulose suspensions (Avicel PH105, FMC Biopolymer, Philadelphia PA) of 50, 70 and $100 \mathrm{~g} / \mathrm{L}$ final concentration were autoclaved twice for $3 \mathrm{~h}$. Between autoclaving sessions, the suspensions were stirred and purged with $\mathrm{N}_{2}$ gas. The medium was prepared in a 5 -L carboy by separately adding each component to the autoclaved cellulose slurry by filter sterilization under anaerobic conditions. The complete medium was then added to the bioreactor under sterile conditions. The bioreactor was inoculated with $5 \mathrm{~mL}-80^{\circ} \mathrm{C}$ freezer stock culture grown on $5 \mathrm{~g} / \mathrm{L}$ Avicel PH105 in MTC $(0.5 \% \mathrm{v} / \mathrm{v})$. The headspace of the bioreactor setup was flushed with $\mathrm{N}_{2}$ gas prior to inoculation.

\section{Pellet nitrogen and protein analysis}

Cell biomass expressed as pellet nitrogen was measured by elemental analysis as described in Holwerda et al. [29].

$1-\mathrm{mL}$ fermentation samples were analyzed for protein content by dividing the sample into a $600-\mu \mathrm{L}$ supernatant fraction and a $400-\mu \mathrm{L}$ pellet fraction. The supernatant protein was analyzed by Bradford assay (Bio-Rad protein assay, Bio-Rad, Hercules, CA) against a serial dilution of bovine serum albumin as standard (Thermo Scientific, Rockford, IL). The pellet was rinsed with $1 \mathrm{~mL}$ of distilled water, lysed by adding $1 \mathrm{~mL}$ of $0.2 \mathrm{M} \mathrm{NaOH}$ with $1 \% \mathrm{w} / \mathrm{v}$ SDS, and incubated for $45 \mathrm{~min}$ at room temperature with intermittent vortex mixing. After incubation the $\mathrm{pH}$ was neutralized by adding $50 \mu \mathrm{L}$ of $4 \mathrm{~N} \mathrm{HCl}$ and the mixture was centrifuged at 21,000 $\mathrm{rcf}(15,000 \mathrm{rpm})$ for $5 \mathrm{~min}$. The protein in the supernatant of the pellet protein fraction was quantified by bicinchoninic acid (BCA) assay (Pierce Protein assay kit, Thermo Scientific, Rockford IL) with a serial dilution of bovine serum albumin as standard. No distinction was made for cellulosome-associated protein. The amount of nitrogen in protein was taken as $0.161 \mathrm{~g} / \mathrm{g}$ [74].

\section{Residual substrate}

Residual substrate was determined by quantitative saccharification on triplicate 1-mL samples; see also Holwerda et al. [46].

\section{Fermentation products}

Ethanol, lactate, formate, acetate, pyruvate, fumarate, pyroglutamate, isobutanol, meso-2,3-butanediol, and RR/ SS-2,3-butanediol and xylitol were quantified by HPLC (Waters, Milford, MA) with refractive index (RI) and UV detection using an Aminex HPX-87H column (Bio-Rad, Hercules, CA) with a 5-mM sulfuric acid solution eluent. Malate was quantified by colorimetric assay (BioVision, Milpitas, CA).

Since measurements of $\mathrm{CO}_{2}$ are frequently unreliable due to the accumulation of $\mathrm{CO}_{2}$ in the liquid fraction, for the purposes of carbon balances $\mathrm{CO}_{2}$ production in moles was estimated by stoichiometry using the following formulas:

$$
\begin{aligned}
\mathrm{CO}_{2}= & \text { acetate }+ \text { ethanol }- \text { formate } \\
\mathrm{CO}_{2}= & \text { acetate }+ \text { ethanol }- \text { formate } \\
& + \text { L-valine }+2 * \text { isobutanol }- \text { malate }
\end{aligned}
$$

Formula 1 is used when looking at "commonly reported" fermentation products. Formula 2 is a more comprehensive version of formula 1 .

To account for solubilized, non-utilized oligosaccharides present at the end of the fermentation, the sugar content of the supernatant was determined by acid hydrolysis and measured by HPLC.

The higher alcohols 1-propanol, 2-methyl-1-butanol, 3-methyl-1-butanol, isobutanol and the 2,3-butanediols were identified by gas chromatography with flame ionization detector (GC/FID)(Agilent 7890A, RESTEKFAMEWAX, $30 \mathrm{~m}$ column, helium carrier) and by matching retention times to standards on two different liquid chromatography columns: H-column (Agilent 1100, Aminex HPX-87H column, Bio-Rad, Hercules, CA, 5 mM $\mathrm{H}_{2} \mathrm{SO}_{4}, 0.7 \mathrm{~mL} / \mathrm{min}$ ) and P-column (Thermo Spectra, Aminex HPX-87P column, Bio-Rad, Hercules, CA, distilled water, $0.65 \mathrm{~mL} / \mathrm{min}$ ). Refractive index (RI) was used to detect compounds during HPLC analysis. LC-MS was used to identify fumaric acid and pyroglutamate (L-5-oxoproline) (Thermo LTQ, Aminex HPX-87H column with $0.1 \%$ formic acid eluent, $0.7 \mathrm{~mL} / \mathrm{min}$ ). The chiral isomers SS/RR 2,3-butanediol could not be resolved on either the $\mathrm{GC}$ or LC.

\section{Mass spectrometry analysis}

Aliquots of supernatants $(50 \mu \mathrm{L})$ of Clostridium thermocellum cultures and sorbitol (aqueous internal standard added to yield $20 \mathrm{ng}$ per $\mu \mathrm{L}$ injected) were transferred by pipette to a vial and stored at $-20^{\circ} \mathrm{C}$ until analyzed. 
The samples were thawed and concentrated to dryness under a stream of $\mathrm{N}_{2}$. The internal standard was added to correct for subsequent differences in derivatization efficiency and changes in sample volume during heating. Dried extracts were dissolved in $250 \mu \mathrm{L}$ of silylation-grade acetonitrile followed by the addition of $250 \mu \mathrm{L} \mathrm{N}$-methyl$\mathrm{N}$-(trimethylsilyl)trifluoroacetamide (MSTFA) with $1 \%$ trimethylchlorosilane (TMCS) (Thermo Scientific, Bellefonte, $\mathrm{PA})$, and the samples were then heated for $1 \mathrm{~h}$ at $70^{\circ} \mathrm{C}$ to generate trimethylsilyl (TMS) derivatives. After 1 day, $1-\mu \mathrm{L}$ aliquots were injected into an Agilent Technologies Inc. (Santa Clara, CA) 5975C inert XL gas chromatographmass spectrometer, fitted with an Rtx-5MS with Integraguard (5\% diphenyl/95\% dimethyl polysiloxane) $30 \mathrm{~m} \times$ $250 \mu \mathrm{m} \times 0.25 \mu \mathrm{m}$ film thickness capillary column. The standard quadrupole GC-MS was operated in the electron impact $(70 \mathrm{eV})$ ionization mode, targeting six full-spectrum (50 to $650 \mathrm{Da}$ ) scans per second. The gas (helium) flow was $1.3 \mathrm{~mL}$ per minute with the injection port configured in the splitless mode. The injection port, MS source, and MS quad temperatures were $250^{\circ} \mathrm{C}$, $230^{\circ} \mathrm{C}$, and $150^{\circ} \mathrm{C}$, respectively. The initial oven temperature was held at $50^{\circ} \mathrm{C}$ for $2 \mathrm{~min}$ and was programmed to increase at $20^{\circ} \mathrm{C}$ per min to $325^{\circ} \mathrm{C}$ and held for another $11 \mathrm{~min}$, before cycling back to the initial conditions. A large user-created database $(>1,900$ spectra) of mass spectral electron ionization (EI) fragmentation patterns of TMS-derivatized compounds as well as the Wiley Registry 8th Edition combined with NIST 05 mass spectral database were used to identify the metabolites of interest to be quantified. The analyses targeted metabolites related to the isobutanol production pathway. Additional analyses of commercial standards confirmed the presence of xylitol, 2-oxo-isovalerate, RR/SS-2,3-butanediol, meso-2,3-butanediol, and 1,2,3-butanetriol. Peaks were reintegrated and reanalyzed using a key selected ion, characteristic $\mathrm{m} / \mathrm{z}$ fragment, rather than the total ion chromatogram, to minimize integrating co-eluting metabolites. The extracted peaks of known metabolites were scaled back up to the total ion current using predetermined scaling factors. The scaling factor for the internal standard (sorbitol) was used for unidentified metabolites. Peaks were quantified by area integration and the concentrations were normalized to the quantity of the internal standard recovered, and volume of sample processed, derivatized, and injected [75].

\section{Amino acids, vitamins and trace elements}

Supernatants were analyzed for amino acids (ninhydrin method) and B-vitamins, ("vitamin B-panel" by HPLC) by Aminoacids.com (St. Paul, MN). Para-aminobenzoic acid (PABA) was quantified by LC/MS/MS at the Laboratory of Toxicology, Ghent Belgium; see also [76]. An appropriate method for quantification of biotin was not found for concentrations as applied here. Amino acid nitrogen data for non-analyzed time points is inferred by linearization between measured data points $t=3,6,9,12$, and 16 and the assumption that at $t=0$ the concentration of free amino acids approaches zero, as the inoculum was only $0.5 \% \mathrm{v} / \mathrm{v}$.

Trace elements were quantified by inductively coupled plasma mass spectrometry (Agilent 7700x, Santa Clara, CA) at the Trace Elements Analysis Laboratory at Dartmouth College.

\section{Residual medium nitrogen}

Residual nitrogen in ammonia and urea was determined by the "Urea/Ammonia (Rapid) assay procedure" from Megazyme (Bray, Ireland).

\section{Additional files}

Additional file 1: Figure S1. A. Extracted ion $\mathrm{m} / \mathrm{z} 117$ trace of gas chromatography-mass spectrometry electron impact ionization (70 eV) of a microbial supernatant sample indicating the presence of $A$ ) meso-2,3-butanediol and B) RR/SS-2,3-butanediol (top panel). Their corresponding fragmentation patterns are shown in the middle and lower panels, respectively.

Additional file 2: Figure S1. B. Total ion current traces of gas chromatography-mass spectrometry electron impact ionization (70 eV) of standards of A) meso-2,3-butanediol and B) RR/SS-2,3-butanediol (top panel). Their corresponding fragmentation patterns are shown in the middle and lower panels, respectively.

Additional file 3: Figure S2. A. Elution profile (A) and electron impact (70 eV) fragmentation pattern (B) of isobutanol sample partitioned from supernatant with diethyl ether.

Additional file 4: Figure S2. B. Electron impact $(70 \mathrm{eV})$ fragmentation pattern of isobutanol from sample versus Wiley database match.

Additional file 5: Figure S2. C. Elution profile (A) and electron impact $(70 \mathrm{eV}$ ) fragmentation pattern (B) of isobutanol standard (1\%) in diethyl ether solvent.

Additional file 6: Figure S2. D. Electron impact (70 eV) fragmentation pattern of isobutanol standard versus Wiley database.

\section{Abbreviations}

2M1B: 2-methyl-1-butanol; 3M1B: 3-methyl-1-butanol; BCA: bicinchoninic acid; CBP: consolidated bioprocessing; El: electron ionization; MSTFA: N-Methyl-N-(trimethylsilyl)trifluoroacetamide; MTC: Medium for Thermophilic Clostridia; PABA: para-aminobenzoic acid; Rl: refractive index;

TMCS: trimethylchlorosilane; TMS: trimethylsilyl.

\section{Competing interests}

PGT and LRL are affiliated with Mascoma Corporation, which partly funded this research.

\section{Authors' contributions}

EKH, JPVD, and LRL conceived of the study. EKH performed all experiments presented herein. EKH, PGT, DGO, DAN, NLE and TJT carried out the experimental analyses. DGO assisted in drafting the manuscript. EKH drafted the manuscript together with JPvD and LRL, who also supervised the work. All authors read and approved the final manuscript.

\section{Acknowledgements}

This work was supported by the BioEnergy Science Center (BESC). The BioEnergy Science Center is a U.S. Department of Energy Bioenergy Research Center supported by the Office of Biological and Environmental Research in the DOE Office of Science. Additional support was provided by Mascoma 
Corporation. The authors would like to acknowledge Professor Brian Jackson, Rodney Baker, and Emily Pierson at the Trace Elements Laboratory at Dartmouth College for the quantification of trace elements and Professor Willy Lambert at the Laboratory of Toxicology, Ghent University, for quantification of PABA

Notice: This manuscript has been authored by Dartmouth College under Subcontract Number 4000115284 and Contract Number DE-AC05-00OR22725 with the U.S. Department of Energy. The United States Government retains and the publisher, by accepting the article for publication, acknowledges that the United States Government retains a non-exclusive, paid-up, irrevocable, world-wide license to publish or reproduce the published form of this manuscript or allow others to do so, for United States Government purposes.

\section{Author details}

'Thayer School of Engineering, Dartmouth College, Hanover, NH 03755, USA. ${ }^{2}$ BioEnergy Science Center, Oak Ridge, TN 37830, USA. ${ }^{3}$ Mascoma Corporation, Lebanon, NH 03766, USA. ${ }^{4}$ Department of Bacteriology, University of Wisconsin-Madison, Madison, WI 53706, USA. ${ }^{5}$ Biosciences Division, Oak Ridge National Laboratory, Oak Ridge, TN 37830, USA. ${ }^{6}$ Emeritus Industrial Biotechnology of Delft University of Technology, Delft, BC 2628, The Netherlands.

Received: 10 May 2014 Accepted: 3 October 2014

Published online: 21 October 2014

\section{References}

1. Bayer EA, Belaich JP, Shoham Y, Lamed R: The cellulosomes: multienzyme machines for degradation of plant cell wall polysaccharides. Annu Rev Microbiol 2004, 58:521-554

2. Demain AL, Newcomb M, Wu JHD: Cellulase, clostridia, and ethanol. Microbiol Mol Biol Rev 2005, 69:124-154.

3. Lynd LR, Van Zyl WH, McBride JE, Laser M: Consolidated bioprocessing of cellulosic biomass: an update. Curr Opin in Biotechnol 2005, 16:577-583.

4. McBee RH: The anaerobic thermophilic cellulolytic bacteria. Bacterio/ Rev 1950, 14:51-63.

5. McBee RH: The characteristics of Clostridium thermocellum. J Bacteriol 1954, 67:505-506.

6. Sparling R, Islam R, Cicek N, Carere C, Chow H, Levin DB: Formate synthesis by Clostridium thermocellum during anaerobic fermentation. Can $J$ Microbiol 2006, 52:681-688.

7. Ellis LD, Holwerda EK, Hogsett D, Rogers S, Shao X, Tschaplinski T, Thorne $P$, Lynd LR: Closing the carbon balance for fermentation by Clostridium thermocellum (ATCC 27405). Bioresource Technol 2012, 103:293-299.

8. van der Veen D, Lo J, Brown SD, Johnson CM, Tschaplinski TJ, Martin M, Engle NL, van den Berg RA, Argyros AD, Caiazza NC, Guss AM, Lynd LR: Characterization of Clostridium thermocellum strains with disrupted fermentation end-product pathways. J Ind Microbiol \& Biotechnol 2013, 40:725-734

9. Zhou J, Olson DG, Argyros DA, Deng Y, Van Gulik WM, Van Dijken JP, Lynd LR: An atypical glycolysis in Clostridium thermocellum. Appl Environ Microbiol 2013, 79:3000-3008.

10. Argyros DA, Tripathi SA, Barrett TF, Rogers SR, Feinberg LF, Olson DG, Foden JM, Miller BB, Lynd LR, Hogsett DA, Caiazza NC: High ethanol titers from cellulose using metabolically engineered thermophilic, anaerobic microbes. Appl Environ Microbiol 2011, 77:8288-8294.

11. Tripathi SA, Olson DG, Argyros DA, Miller BB, Barrett TF, Murphy DM, McCool JD, Warner AK, Rajgarhia VB, Lynd LR, Hogsett DA, Caiazza NC Development of pyrF-based genetic system for targeted gene deletion in Clostridium thermocellum and creation of a pta mutant. Appl Environ Microbiol 2010, 76:6591-6599.

12. Mohr G, Hong W, Zhang J, Cui G-Z, Yang Y, Cui Q, Liu Y-j, Lambowitz AM: A targetron system for gene targeting in thermophiles and its application in Clostridium thermocellum. PLoS One 2013, 8:e69032.

13. Weimer PJ, Zeikus JG: Fermentation of cellulose and cellobiose by Clostridium thermocellum in absence and presence of Methanobacterium thermoautotrophicum. Appl Environ Microbiol 1977, 33:289-297.

14. Garcia-Martinez DV, Shinmyo A, Madia A, Demain AL: Studies on cellulase production by Clostridium thermocellum. Eur J Appl Microbiol Biotechnol 1980, 9:189-197.
15. Johnson EA, Madia A, Demain AL: Chemically defined minimal medium for growth of the anaerobic cellulolytic thermophile Clostridium thermocellum. App/ Environ Microbiol 1981, 41:1060-1062.

16. Saddler JN, Chan MKH: Optimization of Clostridium thermocellum growth on cellulose and pretreated wood substrates. Eur J Appl Microbiol Biotechnol 1982, 16:99-104

17. Bayer EA, Kenig R, Lamed R: Adherence of Clostridium thermocellum to cellulose. J Bacterio/ 1983, 156:818-827.

18. Kurose N, Yagyu J, Miyazaki T, Uchida M, Hanai S, Obayashi A: Evaluation of ethanol productivity from cellulose by Clostridium thermocellum. J Ferm Technol 1986, 64:447-450.

19. Vuillet $\mathrm{S}$, Spinnler HE, Blachere $\mathrm{H}$ : Analysis of amino-acid requirements of Clostridium thermocellum. Appl Microbiol Biotechnol 1986, 23:496-498.

20. Lynd LR, Grethlein HE, Wolkin RH: Fermentation of cellulosic substrates in batch and continuous culture by Clostridium thermocellum. Appl Environ Microbiol 1989, 55:3131-3139.

21. Nochur SV, Demain AL, Roberts MF: Carbohydrate utilization by Clostridium thermocellum - importance of internal $\mathrm{pH}$ in regulating growth. Enz Microbial Technol 1992, 14:338-349.

22. Strobel HJ: Growth of the thermophilic bacterium Clostridium thermocellum in continuous cultures. Curr Microbiol 1995, 31:210-214.

23. Knutson BL, Strobel HJ, Nokes SE, Dawson KA, Berberich JA, Jones CR: Effect of pressurized solvents on ethanol production by the thermophilic bacterium Clostridium thermocellum. J Supercrit Fluids 1999, 16:149-156.

24. Bothun GD, Knutson BL, Berberich JA, Strobel HJ, Nokes SE: Metabolic selectivity and growth of Clostridium thermocellum in continuous culture under elevated hydrostatic pressure. Appl Microbiol Biotechnol 2004, 65:149-157.

25. Lu YP, Zhang YHP, Lynd LR: Enzyme-microbe synergy during cellulose hydrolysis by Clostridium thermocellum. Proc Natl Acad Sci U S A 2006, 103:16165-16169.

26. Islam R, Cicek N, Sparling R, Levin D: Effect of substrate loading on hydrogen production during anaerobic fermentation by Clostridium thermocellum 27405. Appl Microbiol Biotechnol 2006, 72:576-583.

27. Magnusson L, Islam R, Sparling R, Levin D, Cicek N: Direct hydrogen production from cellulosic waste materials with a single-step dark fermentation process. Internat/ J Hydr Ener 2008, 33:5398-5403.

28. Raman B, Pan C, Hurst GB, Rodriguez M Jr, McKeown CK, Lankford PK, Samatova NF, Mielenz JR: Impact of pretreated switchgrass and biomass carbohydrates on Clostridium thermocellum ATCC 27405 cellulosome composition: a quantitative proteomic analysis. PLoS One 2009, 4:e5271.

29. Holwerda EK, Ellis LD, Lynd LR: Development and evaluation of methods to infer biosynthesis and substrate consumption in cultures of cellulolytic microorganisms. Biotechnol Bioeng 2013, 110:2380-2388.

30. Olson DG, Giannone RJ, Hettich RL, Lynd LR: Role of the CipA scaffoldin protein in cellulose solubilization, as determined by targeted gene deletion and complementation in Clostridium thermocellum. J Bacterio/ 2013, 195:733-739.

31. Currie DH, Herring CD, Guss AM, Olson DG, Hogsett DA, Lynd LR: Functional heterologous expression of an engineered full length CipA from Clostridium thermocellum in Thermoanaerobacterium saccharolyticum. Biotechnol Biofuels 2013, 6:32

32. Tailliez P, Girard H, Millet J, Beguin P: Enhanced cellulose fermentation by an asporogenous and ethanol-tolerant mutant of Clostridiumthermocellum. Appl Environ Microbiol 1989, 55:207-211.

33. Wang DIC, Avgerinos GC, Biocic I, Wang SD, Fang HY: Ethanol from cellulosic biomass. Philos T Soc B 1983, 300:323-333.

34. Hogsett D: Cellulose hydrolysis and fermentation by Clostridium thermocellum for the production of ethanol. PhD thesis. Dartmouth College, Thayer School of Engineering; 1995

35. Viljoen JA, Fred EB, Peterson WH: The fermentation of cellulose by thermophilic bacteria. J Agric Sci 1926, 16:1-17.

36. Freier D, Mothershed CP, Wiegel J: Characterizations of Clostridium thermocellum JW20. Appl Environ Microbiol 1988, 54:204-211.

37. Ng TK, Weimer PJ, Zeikus JG: Cellulolytic and physiological properties of Clostridium thermocellum. Arch Microbiol 1977, 114:1-7.

38. Lamed R, Zeikus JG: Ethanol production by thermophilic bacteria - relationship between fermentation product yields and catabolic enzyme activities in Clostridium thermocellum and Thermoanaerobium brockii. J Bacterio/ 1980, 144:569-578.

39. Erbeznik M, Jones CR, Dawson KA, Strobel HJ: Clostridium thermocellum JW20 (ATCC 31549) is a coculture with Thermoanaerobacter ethanolicus. Appl Environ Microbiol 1997, 63:2949-2951. 
40. Sato KJ, Goto SG, Yonemura ST, Sekine KJ, Okuma EK, Takagi YS, Honnami KY, Saiki T: Effects of yeast extract and vitamin B-12 on ethanol-production from cellulose by Clostridium thermocellum I-1-B. Appl Environ Microbiol 1992, 58:734-736.

41. Mori Y: Nutritional interdependence between Thermoanaerobacter thermohydrosulfuricus and Clostridium thermocellum. Arch Microbiol 1995, 164:152-154.

42. Ng TK, Benbassat A, Zeikus JG: Ethanol production by thermophilic bacteria - fermentation of cellulosic substrate by cocultures of Clostridium thermocellum and Clostridium thermohydrosulfuricum. Appl Environ Microbiol 1981, 41:1337-1343.

43. He Q, Hemme $\mathrm{CL}$, Jiang $\mathrm{H}, \mathrm{He} \mathrm{Z}$, Zhou J: Mechanisms of enhanced cellulosic bioethanol fermentation by co-cultivation of Clostridium and Thermoanaerobacter spp. Bioresour Technol 2011, 102:9586-9592.

44. Humbird D, Mohagheghi A, Dowe N, Schell DJ: Economic impact of total solids loading on enzymatic hydrolysis of dilute acid pretreated corn stover. Biotechnol Prog 2010, 26:1245-1251.

45. Prawitwong P, Waeonukul R, Tachaapaikoon C, Pason P, Ratanakhanokchai K, Deng L, Sermsathanaswadi J, Septiningrum K, Mori Y, Kosugi A: Direct glucose production from lignocellulose using Clostridium thermocellum cultures supplemented with a thermostable beta-glucosidase. Biotechn Biofuels 2013, 6:184

46. Holwerda E, Hirst K, Lynd L: A defined growth medium with very low background carbon for culturing Clostridium thermocellum. J Ind Microbiol Biotechnol 2012, 39:943-947.

47. Stevenson IL: Production of extracellular amino acids by rumen bacteria. Can J Microbiol 1978, 24:1236-1241.

48. Kengen SWM, Stams AJM: Formation of L-alanine as a reduced end-product in carbohydrate fermentation by the hyperthermophilic archaeon Pyrococcus furiosus. Arch Microbiol 1994, 161:168-175.

49. Szech U, Braun M, Kleiner D: Uptake and excretion of amino-acids by saccharolytic clostridia. FEMS Microbiol Lett 1989, 58:11-14.

50. Tempest DW, Meers $J \mathrm{~L}$, Brown CM: Influence of environment on content and composition of microbial free amino acid pools. J Gen Microbiol 1970, 64:171-185.

51. Yamamoto K, Murakami R, Takamura Y: Isoprenoid quinone, cellular fatty acid composition and diaminopimelic acid isomers of newly classified thermophilic anaerobic Gram-positive bacteria. FEMS Microbiol Lett 1998, 161:351-358.

52. Baskaran S, Ahn HJ, Lynd LR: Investigation of the ethanol tolerance of Clostridium thermosaccharolyticum in continuous culture. Biotechnol Progr 1995, 11:276-281.

53. Lynd LR, Baskaran S, Casten S: Salt accumulation resulting from base added for $\mathrm{pH}$ control, and not ethanol, limits growth of Thermoanaerobacterium thermosaccharolyticum HG-8 at elevated feed xylose concentrations in continuous culture. Biotechnol Progr 2001, 17:118-125.

54. Steiner E, Scott J, Minton NP, Winzer K: An agr quorum sensing system that regulates granulose formation and sporulation in Clostridium acetobutylicum. Appl Environ Microbiol 2012, 78:1113-1122.

55. Burrell PC: The detection of environmental autoinducing peptide quorum-sensing genes from an uncultured Clostridium sp. in landfill leachate reactor biomass. Lett Appl Microbiol 2006, 43:455-460.

56. Wilson CM, Rodriguez M, Johnson CM, Martin SL, Chu TM, Wolfinger RD, Hauser LJ, Land ML, Klingeman DM, Syed MH, Ragauskas AJ, Tschaplinski TJ, Mielenz JR, Brown SD: Global transcriptome analysis of Clostridium thermocellum ATCC 27405 during growth on dilute acid pretreated Populus and switchgrass. Biotechnol Biofuels 2013, 6:18.

57. Latif F, Rajoka Ml: Production of ethanol and xylitol from corn cobs by yeasts. Bioresour Technol 2001, 77:57-63.

58. Rao RS, Jyothi CP, Prakasham RS, Sarma PN, Rao LV: Xylitol production from corn fiber and sugarcane bagasse hydrolysates by Candida tropicalis. Bioresour Technol 2006, 97:1974-1978.

59. Airaudo CB, Gaytesorbier A, Armand P: Stability of glutamine and pyroglutamic acid under model system conditions - influence of physical and technological factors. J Food Sci 1987, 52:1750-1752.

60. Snowden MK, Baxter JH, Bergana MM, Reyzer I, Pound V: Stability of $\mathrm{N}$-acetylglutamine and glutamine in aqueous solution and in a liquid nutritional product by an improved HPLC method. J Food Sci 2002. 67:384-389.
61. Park CB, Ryu DDY, Lee SB: Inhibitory effect of L-pyroglutamate on extremophiles: correlation with growth temperature and $\mathrm{pH}$. FEMS Microbiol Lett 2003, 221:187-190.

62. Zhang K, Sawaya MR, Eisenberg DS, Liao JC: Expanding metabolism for biosynthesis of nonnatural alcohols. Proc Natl Acad Sci USA 2008, 105:20653-20658.

63. Higashide W, Li YC, Yang YF, Liao JC: Metabolic engineering of Clostridium cellulolyticum for production of isobutanol from cellulose. Appl Environ Microbiol 2011, 77:2727-2733.

64. Kanehisa M, Goto S: KEGG: Kyoto Encyclopedia of Genes and Genomes. Nucleic Acids Res 2000, 28:27-30.

65. Xiao ZJ, Wang XM, Huang YL, Huo FF, Zhu XK, Xi LJ, Lu JR: Thermophilic fermentation of acetoin and 2,3-butanediol by a novel Geobacillus strain. Biotechnol Biofuels 2012, 5:11.

66. Celinska E, Grajek W: Biotechnological production of 2,3-butanediol current state and prospects. Biotechnol Adv 2009, 27:715-725.

67. Siemerink MAJ, Kuit W, Contreras AML, Eggink G, van der Oost J, Kengen SWM: D-2,3-Butanediol production due to heterologous expression of an acetoin reductase in Clostridium acetobutylicum. Appl Environ Microbiol 2011, 77:2582-2588

68. Yu EKC, Chan MKH, Saddler JN: Butanediol production from lignocellulosic substrates by Klebsiella pneomoniae grown in sequential co-culture with Clostridium thermocellum. Appl Microbiol Biotechnol 1985, 22:399-404.

69. Guedon E, Payot S, Desvaux M, Petitdemange H: Relationships between cellobiose catabolism, enzyme levels, and metabolic intermediates in Clostridium cellulolyticum grown in a synthetic medium. Biotechnol Bioeng 2000, 67:327-335.

70. Desvaux M, Guedon E, Petitdemange H: Cellulose catabolism by Clostridium cellulolyticum growing in batch culture on defined medium. Appl Environ Microbiol 2000, 66:2461-2470.

71. Guedon E, Desvaux M, Petitdemange H: Improvement of cellulolytic properties of Clostridium cellulolyticum by metabolic engineering. Appl Environ Microbiol 2002, 68:53-58.

72. Saddler JN, Chan MKH: Conversion of pretreated lignocellulosic substrate to ethanol by Clostridium thermocellum in mono-culture and co-culture with Clostridium thermosaccharolyticum and Clostridium thermohydrosulphuricum. Can J Microbiol 1984, 30:212-220.

73. Venkateswaran S, Demain AL: The Clostridium thermocellum-Clostridium thermosaccharolyticum ethanol-production process - nutritional studies and scale-down. Chem Eng Commun 1986, 45:53-60.

74. Rouwenhorst RJ, Jzn JF, Scheffers WA, Vandijken JP: Determination of protein concentration by total organic -carbon analysis. J Biochem Bioph Methods 1991, 22:119-128

75. Li YC, Tschaplinski TJ, Engle NL, Hamilton CY, Rodriguez M, Liao JC, Schadt CW, Guss AM, Yang YF, Graham DE: Combined inactivation of the Clostridium cellulolyticum lactate and malate dehydrogenase genes substantially increases ethanol yield from cellulose and switchgrass fermentations. Biotechnol Biofuels 2012, 5:13.

76. Zhang GF, Mortier KA, Storozhenko S, Van De Steene J, Van Der Straeten D, Lambert WE: Free and total para-aminobenzoic acid analysis in plants with high-performance liquid chromatography/tandem mass spectrometry. Rapid Commun Mass Sp 2005, 19:963-969.

doi:10.1186/s13068-014-0155-1

Cite this article as: Holwerda et al: The exometabolome of Clostridium thermocellum reveals overflow metabolism at high cellulose loading. Biotechnology for Biofuels 2014 7:155 